\title{
A Novel and Compact Circularly Polarized Antenna for 5G Wireless Local Area Network Application
}

\author{
Swetha Ravikanti ${ }^{*}$ (Research Scholar, National Institute of Technology, Warangal, India), \\ L. Anjaneyulu (Professor, National Institute of Technology, Warangal, India)
}

\begin{abstract}
The research paper presents a novel and compact circularly polarized (CP) antenna for a 5G wireless local area network (WLAN) application. It consists of a circular patch and a coaxial probe feed radiator. Circular polarization $(C P)$ is attained by symmetric semi-circular slits of radius $r_{1}$ at three edges of a circular path with $90^{\circ}$ in direction, and the other semicircular slit is of different radius $r_{2}$. To improve the impedance bandwidth and axial ratio, the radius of the fourth semicircular slit on circular patch antenna is varied. The design is verified by fabricating a compact antenna of $0.65 \lambda_{0} \times 0.65 \lambda_{0} \times 0.01 \lambda_{0}$. The measured $10 \mathrm{~dB}$ impedance bandwidth is $3.9 \%(5.36-5.56 \mathrm{GHz}), 3-\mathrm{dB}$ axial ratio bandwidth is $1.1 \%(5.43-5.49 \mathrm{GHz})$ and gain of $6.6 \mathrm{dBi}$ at resonant frequency of $5.37 \mathrm{GHz}$ is obtained. The authors also describe two-dimensional radiation patterns of azimuth and elevation plane surface current distribution of the $C P$ patch, VSWR $<2$. The proposed CP antenna is suitable for the $5 G$ WLAN application. The proposed design is compared with various techniques in literature and tabulated. The measured results are also discussed and they are in good agreement with simulated results.
\end{abstract}

Keywords - 5G WLAN application; Circular polarization; Microstrip antenna; Microwave communication; Semi-circular slits.

\section{INTRODUCTION}

As the days pass on, people's usage of wireless handheld devices is increasing along with the requirement for high-speed networks, i.e., $5 \mathrm{G}$ wireless communication. In $1 \mathrm{G}, 2 \mathrm{G} \& 3 \mathrm{G}$, voice is transmitted in analogue form, digital form and then brought to the mobile data. $4 \mathrm{G}$ introduced the era of portable broadband. $5 \mathrm{G}$ wireless networks provide high-speed, ultra-low latency, more reliable and increased capacity. The compact microstrip circularly polarized antenna for $5 \mathrm{G}$ wireless communication is in high demand since the advances in semiconductor technology for wireless technology have led to a reduction in cost. Federal Communications Commission (FCC) adopted a new regulation in the $5 \mathrm{GHz}$ band, with an additional $400 \mathrm{MHz}$ band, which resulted in a standard IEEE 802.11ac for 5G WLAN application [1]-[3].

Microstrip antenna is of lightweight, low volume, thin profile configuration at low fabrication cost, as well as it is easily integrated with microwave circuits. Circular polarization is opted due to low polarization losses, low multipath interferences, polarization mismatch, and reduced Faraday rotation effects. The single probe feed structure reduces complexity, size, and it is characterised by ease of installation onto the microstrip patch [4], [5].

There is circular polarization (CP) due to the orthogonal field components of electric fields [6]. Various techniques are used to enhance the bandwidth of $\mathrm{CP}$ antennas such as folding the edge of the radiating patch antenna with slots loaded; with these techniques, the size of the antenna reduces to $44.8 \%$, so that the antenna appropriatness for the $5 \mathrm{G}$ mobile phone is discussed in [7]. On the microstrip patch embedding, the substrate integrates a meandering probe feed for $5 \mathrm{G}$ wireless fidelity (Wi-Fi) to improve the CP antenna bandwidth [8].

Enhancement of bandwidth with CP can also be obtained by truncating the corners [9], [10], virtual shorting [11], slit formation at the edges [12]. Slot antenna is backed in substrate integrated waveguide cavity, an antenna can produce $\mathrm{CP}$, but the size is large [13]. Shorting the patch in the quasi magneticelectric region is studied in [14]. Slotted patch is created symmetrical on the patch [15]. Loading the CP antenna with substrate integrated waveguide cavity is discussed in [16]. Cross-slot with unequal lengths on the circular patch results in CP [17]. Directive triangular EBG antenna is designed to obtain high directivity and bandwidth [18]. Other forms of CP antennas are reported in [19]-[21].

A novel and compact circularly polarized antenna with a single probe feed is proposed for WLAN use. The antenna geometry is given in Section II. In Section III, interpretations of the simulated results and parametric analysis are discussed. Measured results and surface current distribution of the design are discussed in Section IV, and conclusions are given in Section V.

\section{ANTENNA GEOMETRY}

The structure of the antenna is displayed in Fig. 1 (a), and Fig. 1 (b) shows the cross-sectional view. The proposed circular patch antenna is aimed at a resonant frequency of $5.37 \mathrm{GHz}$, with radius ' $r$ ' on a square substrate of thickness ' $t$.' Rogers RT Duroid 5880 is used as a substrate $\left(t=0.787 \mathrm{~mm}, \varepsilon_{\mathrm{r}}=2.2\right.$, $\tan \delta=0.005)$ and the fabricated antenna is shown in Fig. 2. The antenna is fed through the coaxial feed for proper impedance matching.

\footnotetext{
${ }^{*}$ Corresponding author.

E-mail: swetha.rks@nitw.ac.in
} 
In antenna geometry, a circular sector portion is removed at $\theta=90^{\circ}$ edges of the four quadrants to surge the electrical length of the patch, which results in better radiation characteristics. The radius $\left(r_{1}\right)$ of the circular sector is equal at the three quadrants, but at the fourth quadrant, the radius $\left(r_{2}\right)$ is increased to create asymmetry, which results in circular polarization.

Microstrip antennas resemble dielectric-loaded cavities, and they parade higher-order resonances. The normalized fields inside the dielectric substrate can originate more precisely by considering that region is a cavity bounded by electric conductors and magnetic walls beside the perimeter of the patch. Based on the cavity model formulation, a design technique is outlined, as shown below. The process adopts that the identified information includes the dielectric constant of the substrate $\left(\varepsilon_{\mathrm{r}}\right)$, the resonant frequency $\left(f_{\mathrm{r}}\right)$, and the height of the substrate $h$. The radius $r$ of the circular patch as a function of $h$ and $\varepsilon$ is given by [22].

$$
r=\frac{F}{\sqrt{1+\frac{2 h}{\pi \varepsilon r F}\left[\ln \left(\frac{\pi F}{2 h}\right)+1.7726\right]}},
$$

where $F$ is given below:

$$
F=\frac{8.791 \times 10^{9}}{f_{\mathrm{r}} \sqrt{\varepsilon_{\mathrm{r}}}} .
$$

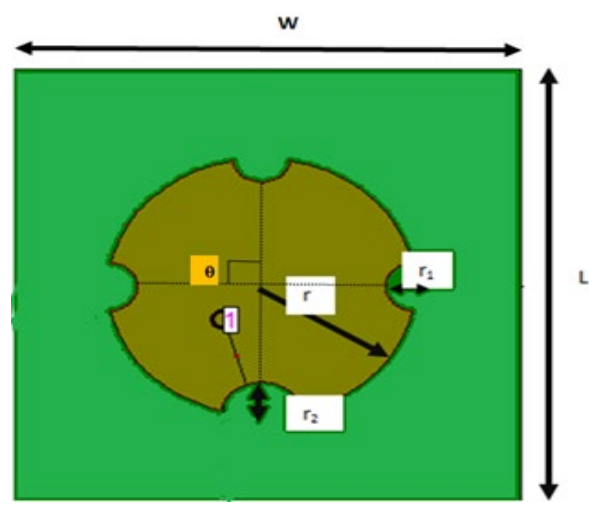

(a)

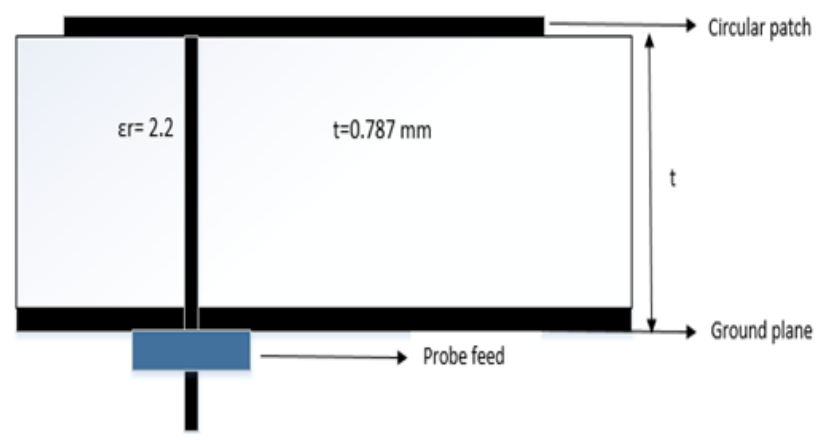

(b)

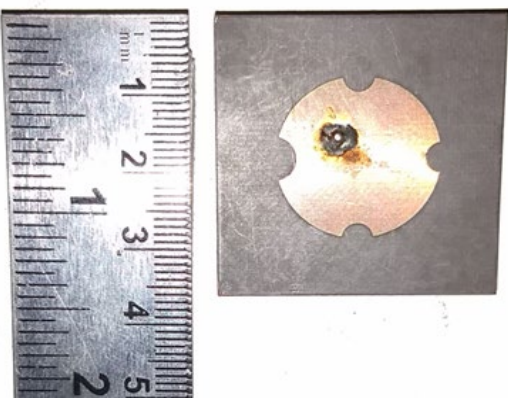

Fig. 2. The fabricated antenna.

\section{INTERPRETATION OF THE SIMULATED RESULTS}

On the circular patch, asymmetry is generated by perturbing the structure with semi-circular slits at four sides of the patch, which results in circular polarization. The feed position is optimized at $(-2.7,-2.7)$ with reverence to the centre of the patch. The value of $r_{2}$ is optimized to give better performance. The designed parameters of antenna are shown in Table I.

\section{Parametric Analysis}

The effect of radius $r_{2}$ of the semi-circular slit on the return loss, impedance bandwidth, gain, etc. is evaluated by varying its value. Table II shows the performance parameters of the proposed antenna for altered values of $r_{2}$ and the corresponding return loss, and axial ratio curves are shown in Figs. 3, 4. By several iterations, the value of $r_{2}$ is fixed at $2.9 \mathrm{~mm}$ for the WLAN application band. Change in radius $r_{2}$ results in the shift of resonant frequency, and gradually bandwidth decreases.

TABLE I

ANTENNA DESIGN PARAMETERS

\begin{tabular}{|c|c|c|c|}
\hline Parameter & Value & Parameter & Value \\
\hline$L$ & $36 \mathrm{~mm}$ & $r_{1}$ & $2 \mathrm{~mm}$ \\
\hline$w$ & $36 \mathrm{~mm}$ & $r_{2}$ & $2.9 \mathrm{~mm}$ \\
\hline$r$ & $10.6 \mathrm{~mm}$ & $t$ & $0.787 \mathrm{~mm}$ \\
\hline
\end{tabular}

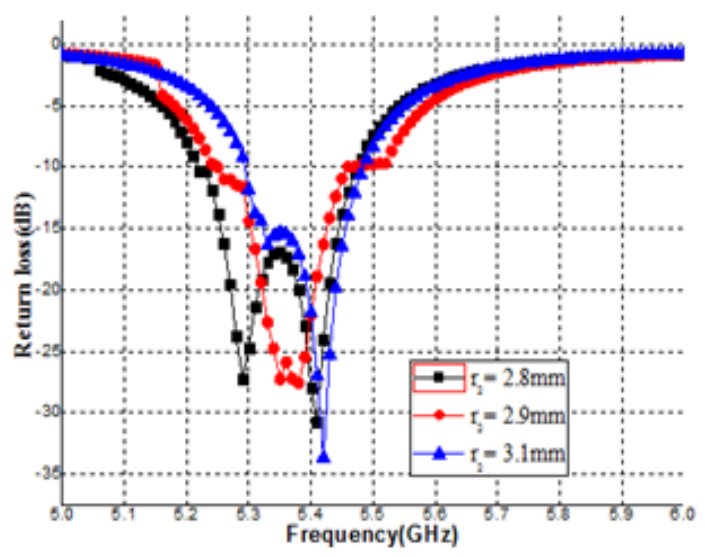

Fig. 3. Return loss for various values of radius $r_{2}$.

Fig. 1. The layout of the proposed antenna: (a) top view; (b) cross-sectional view. 


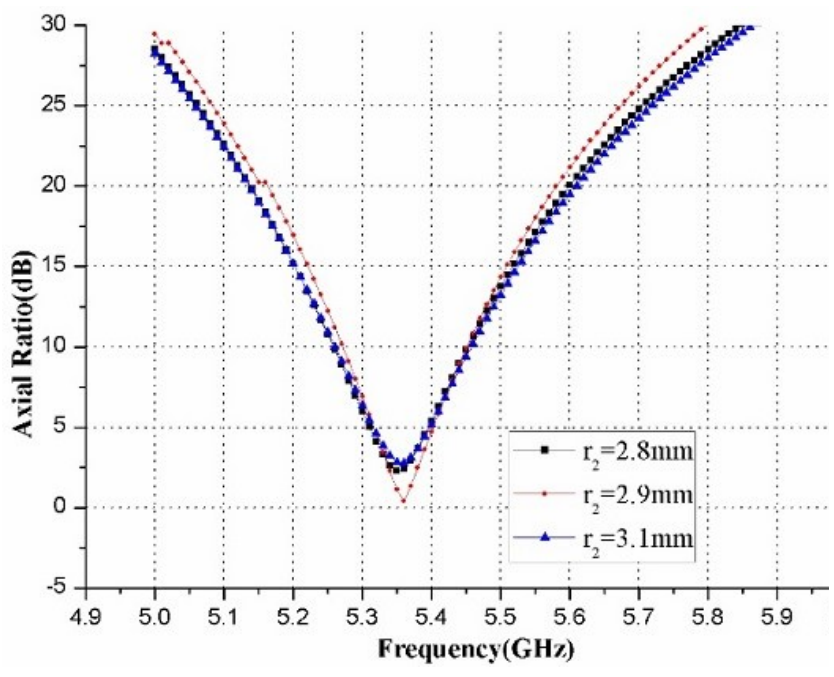

Fig. 4. Return loss for various values of radius $r_{2}$.

\section{MEASURED RESULTS}

\section{A. Return Loss}

The antenna is radiated by feeding on the ground plane; here its coaxial probe feed. When these are in contact with each other, there is an impedance mismatch, which gives a measure of return loss. To check the performance of the proposed design, the return loss is shown in Fig. 5. For the fabricated antenna, the measured return loss is $-28.45 \mathrm{~dB}$ at resonant frequency of $5.37 \mathrm{GHz}$ with $10 \mathrm{~dB}$ impedance bandwidth of $210 \mathrm{MHz}$ in the range of $5.25-5.45 \mathrm{GHz}$. It clearly shows that the designed antenna is suitable for WLAN application.

\section{TABLE II}

EFFECT OF THE RADIUS OF R 2 OF SEMI-CIRCULAR SLIT ON IMPEDANCE BANDWIDTH, AXIAL RATIO, AND GAIN

\begin{tabular}{|c|c|c|c|l|}
\hline $\begin{array}{c}r_{2} \\
\text { value, } \\
\mathrm{mm}\end{array}$ & $\begin{array}{c}\text { Resonant } \\
\text { frequency, } \\
\mathrm{GHz}\end{array}$ & $\begin{array}{c}10 \mathrm{~dB} \text { impedance } \\
\text { bandwidth, GHz }\end{array}$ & $\begin{array}{c}3 \mathrm{~dB} \text { axial ratio } \\
\text { bandwidth, GHz }\end{array}$ & $\begin{array}{c}\text { Gain, } \\
\mathrm{dBi}\end{array}$ \\
\hline 3.1 & 5.51 & $\begin{array}{c}4.71(5.33- \\
5.59 \mathrm{GHz})\end{array}$ & $\begin{array}{c}0.5(5.34- \\
5.37 \mathrm{GHz})\end{array}$ & 6.681 \\
\hline 2.9 & 5.37 & $\begin{array}{c}3.9(5.251- \\
5.45 \mathrm{GHz})\end{array}$ & $\begin{array}{c}1.1(5.33- \\
5.39 \mathrm{GHz})\end{array}$ & 6.638 \\
\hline 2.8 & 5.50 & $\begin{array}{c}4.53(5.33- \\
5.58 \mathrm{GHz})\end{array}$ & $\begin{array}{c}0.7(5.34- \\
5.37 \mathrm{GHz})\end{array}$ & 6.670 \\
\hline
\end{tabular}

\section{B. Gain}

It is the measure of the power of antenna radiation in broadside direction with reference to a reference antenna. The measured gain at resonant frequency of $5.37 \mathrm{GHz}$ is $6.63 \mathrm{dBi}$ and is shown in Fig. 6.

\section{Axial Ratio}

Axial ratio is a factor that indicates the CP of an antenna and is shown in Fig. 7. For the proposed antenna, the measured axial ratio is $0.34 \mathrm{~dB}$, and bandwidth of $60 \mathrm{MHz}$ in the frequency range of $5.33-5.39 \mathrm{GHz}$ is obtained.

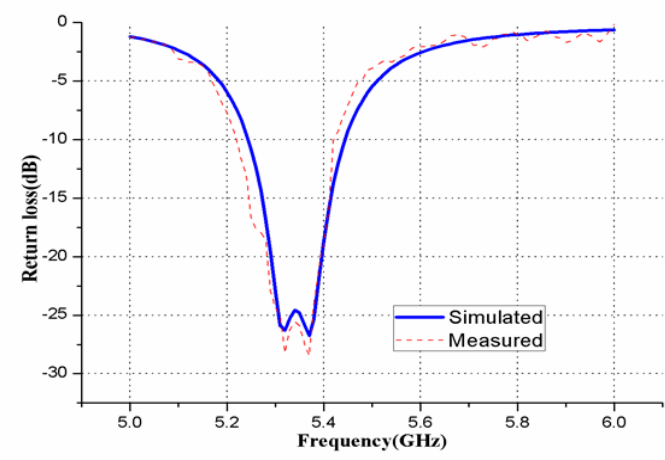

Fig. 5. The return loss of the antenna.

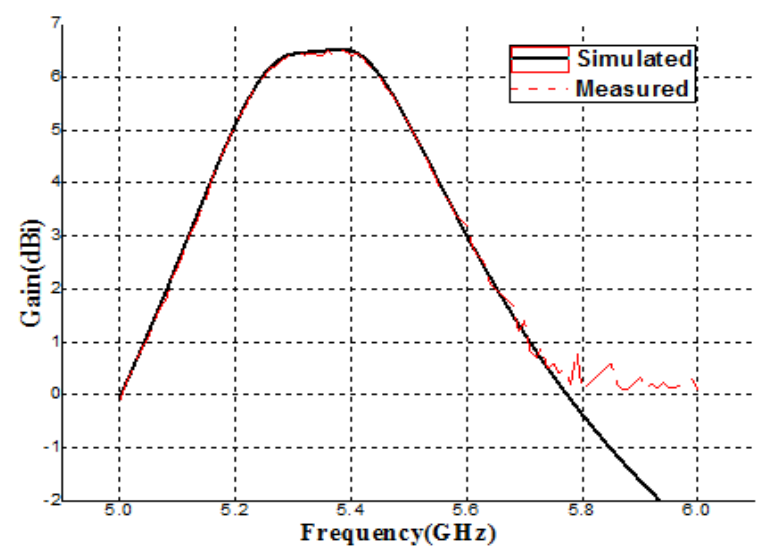

Fig. 6. The gain of the proposed antenna.

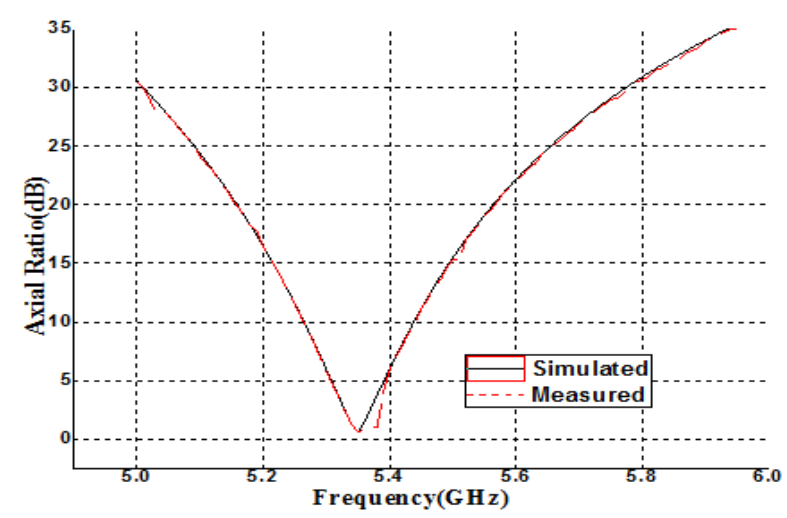

Fig. 7. The axial ratio of the proposed antenna.

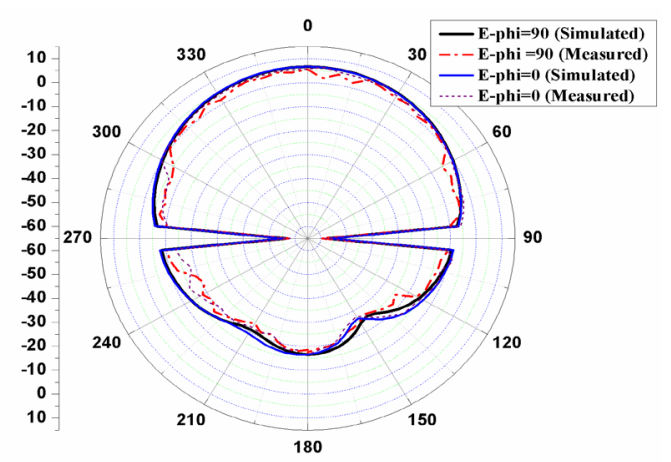

Fig. 8. 2D elevation pattern at the resonant frequency of $5.37 \mathrm{GHz}$ 


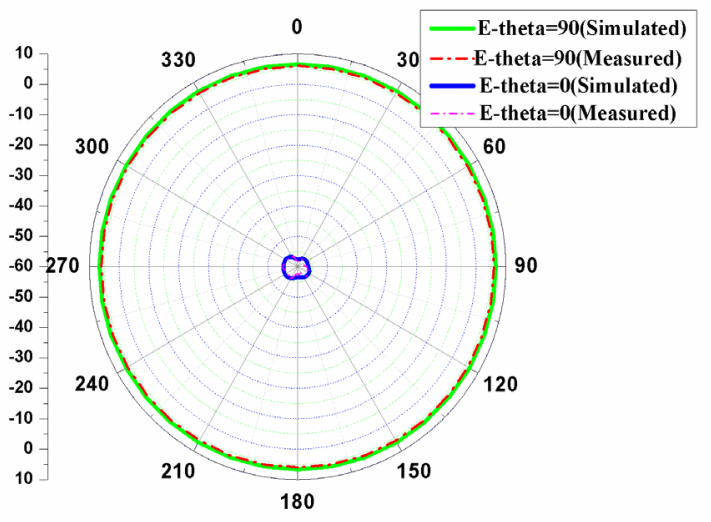

Fig. 9. 2D azimuth pattern at the resonant frequency of $5.37 \mathrm{GHz}$.

\section{Radiation Pattern}

It signifies the orientation of the electric field radiated by the antenna with respect to spatial coordinates. It has two patterns: azimuth and elevation plane, and in the anechoic chamber, measurement setup is made to take the patterns. Figs. 8 and 9 show the simulated, measured azimuth, and elevation planes at the resonant frequency of $5.37 \mathrm{GHz}$. VSWR (Voltage Standing Wave Ratio) is shown in Fig. 10. The radiation efficiency of $74 \%$ is obtained for the proposed antenna (see Fig. 11).

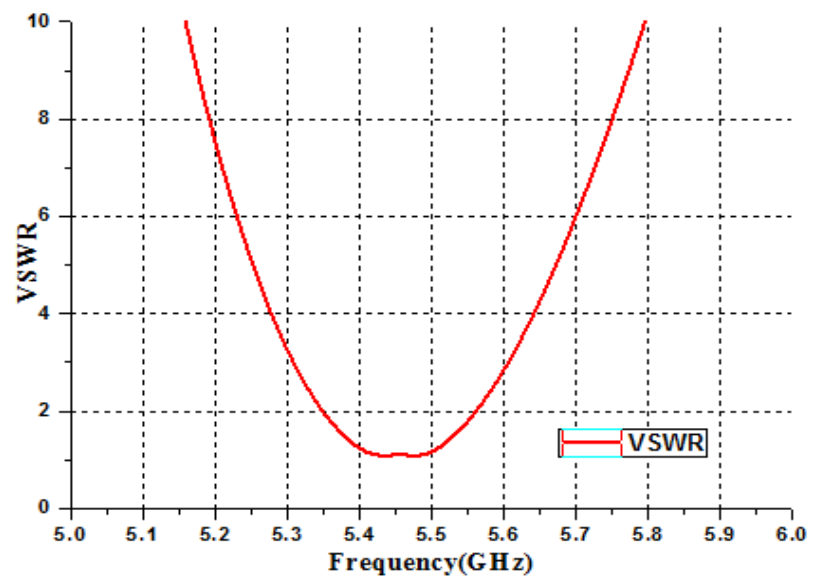

Fig. 10. VSWR of the proposed antenna.

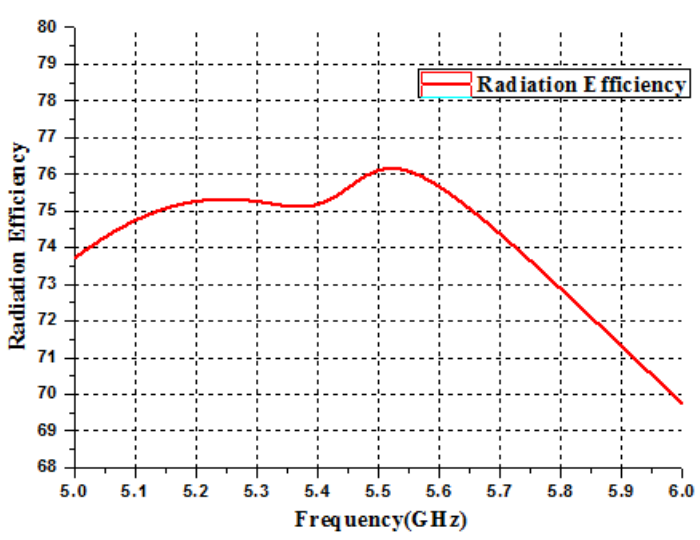

Fig. 11. The radiation efficiency of the proposed antenna.

\section{E. Surface Current Distribution}

To create radiation in antenna, there must be charge acceleration and deceleration, i.e., time-varying current. Usually, the microstrip antenna is excited by a conductor in the centre of the coax serving as the feed probe to couple electromagnetic energy in or out of the patch; charges get accumulated on it. The charge constitutes a current. When a current starts flowing from ground to the patch, parallel to its charge distribution is present at the microstrip surface and ground plane.

Accumulation of charges on to the patch results in the surface current distribution. Figure 12 shows that most of the current resides on the top surface of the patch at the resonant frequency and high current magnitudes at the edges. Consequently, the constituent of the magnetic field, which is oblique to the patch edge, is small. Reactive and resistive components are present at the input impedance of the microstrip antenna. The power radiated by the antenna is due to the resistive elements in antenna power loss by radiation and dielectric mainly due to the presence of imaginary poles and even conduction losses. Current distribution on the microstrip patch surface with the addition of deep semi-circular slit changes current density in magnitude as well as the direction along with the various time intervals. It can be observed in Fig. 12, which in turn creates CP at the respective resonant frequency.

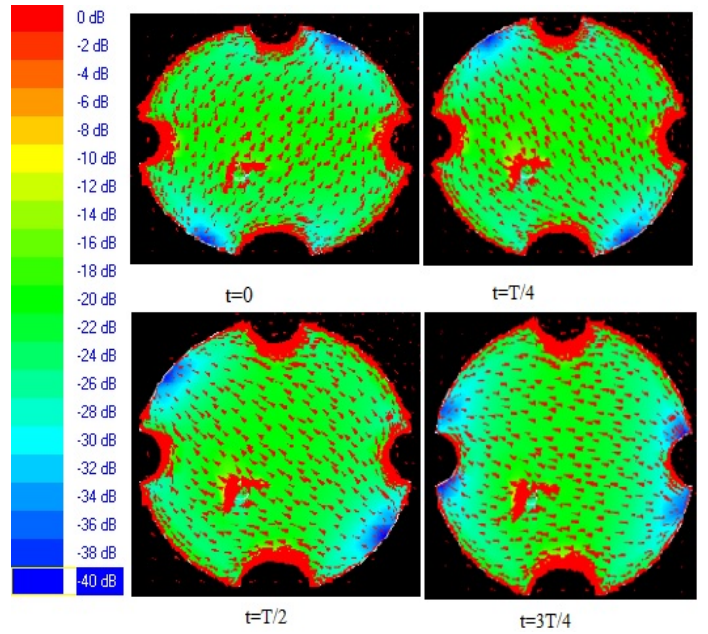

Fig. 12. The surface current distribution of the antenna at the resonant frequency of $5.37 \mathrm{GHz}$.

Now, each vector characterises a major current component in the microstrip radiating patch. The simulated normalized current distributions are illustrated at various time intervals $t=0, T / 4, T / 2$, and $3 T / 4$. It is perceived that the vector sum of the significant components at $t=0$ is orthogonal to that of $t=T / 4$. Thus, a CP mode is generated. In a microstrip patch antenna, the performance parameters like radiation pattern, input impedance, bandwidth, and resonant frequency are controlled by the surface current, which is induced on the microstrip patch. Table III shows the performance comparison of the proposed antenna with some of the existing designs. 
TABLE III

Performance Comparison of the Proposed Antenna With Some of the Existing Designs

\begin{tabular}{|c|c|c|c|c|c|}
\hline References & Frequency, GHz & $\begin{array}{c}10 \mathrm{~dB} \text { impedance } \\
\text { bandwidth, } \% \\
(\mathrm{MHz})\end{array}$ & $\begin{array}{c}3 \mathrm{~dB} \text { axial ratio } \\
\text { bandwidth, } \% \\
(\mathrm{MHz})\end{array}$ & Gain, dBi & Size of the antenna \\
\hline$[11]$ & $2.487-2.501$ & 3.25 & 0.62 & 3.8 & $0.174 \lambda_{0} \times 0.174 \lambda_{0} \times 0.026 \lambda_{0}$ \\
\hline$[12]$ & $2.404-2.416$ & 2.10 & 0.5 & 4.35 & $0.288 \lambda_{0} \times 0.288 \lambda_{0} \times 0.0118 \lambda_{0}$ \\
\hline$[13]$ & $14.38-14.94$ & 4 & 0.83 & $7.1-7.4$ & $1.03 \lambda_{0} \times 0.56 \lambda_{0} \times 0.0372 \lambda_{0}$ \\
\hline$[14]$ & $5.84-6.00$ & 2 & 0.33 & 8.5 & $0.5 \lambda_{0} \times 0.5 \lambda_{0} \times 0.03 \lambda_{0}$ \\
\hline$[15]$ & $2.138-2.230$ & 4.2 & 0.8 & - & $0.436 \lambda_{0} \times 0.436 \lambda_{0} \times 0.0116 \lambda_{0}$ \\
\hline$[16]$ & $5.7-5.8$ & 4.3 & - & $2.3-3.3$ & $1.74 \lambda_{0} \times 0.313 \lambda_{0} \times 0.0386 \lambda_{0}$ \\
\hline$[17]$ & $2.45-2.55$ & 4 & - & $24 \mathrm{~dB}$ (directivity) & - \\
\hline Proposed antenna & $5.35-5.56$ & 3.9 & 1.1 & 6.67 & $0.65 \lambda_{0} \times 0.65 \lambda_{0} \times 0.01 \lambda_{0}$ \\
\hline
\end{tabular}

\section{F. Measurement Setup}

When an antenna is fabricated with a finalized design on aperformance by measuring its performance parameters like return loss, axial ratio, gain, radiation efficiency, and radiation characteristics using the Network Analyser and antenna measurement setup. Here are mostly two types of network analyzers available: scalar and vector network analyzers. Scalar network analyzer measures the magnitudes of transmission and reflection coefficients; however, both the magnitude and phase of the S-parameters are measured by the vector network analyzer. In general, the network analyzer consists of a signal processor, calibration kit, display unit, and microwave source. To evaluate the performance, parameters of the antenna using a vector network analyzer are calibrated once the ports are matched, as shown in Fig. 13. After the matching is done, the antenna is connected to port 1 and matched load to port 2, as shown in Fig. 14, and Fig. 15 illustrates the measured return loss for the proposed antenna.

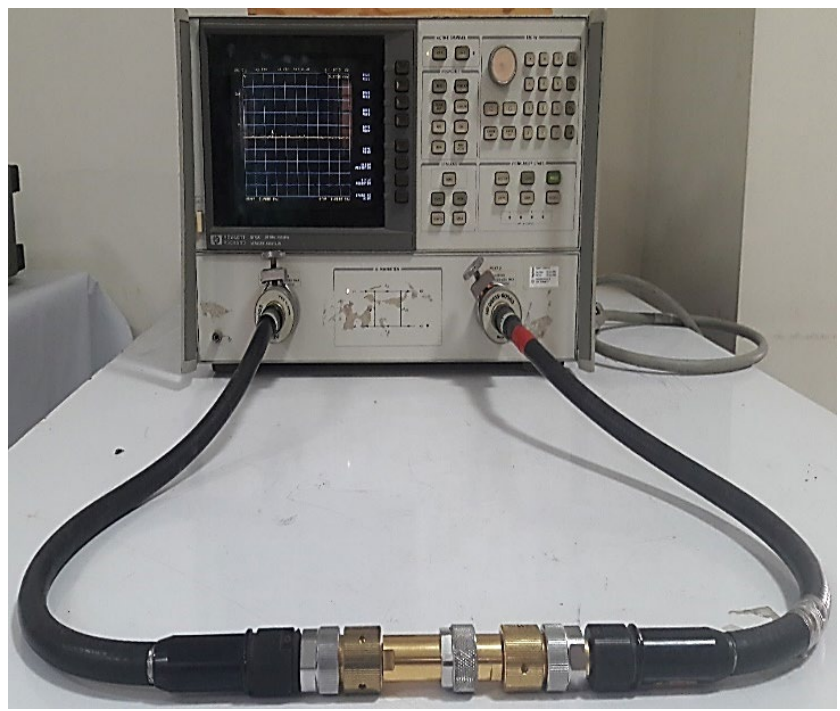

Fig. 13. Ports are connected via a coaxial cable for matching.

\section{G. Discussion of Results}

The performance and radiation characteristics of the proposed design are evaluated by the method of moment technique embedded in a solver called integral equation 3dimensional. Inductive and capacitive loading technique is employed to generate circular polarization, but low return loss is obtained and not compact. Loading of shorting pins creates short from the ground to the patch to get impedance match and high gain but low impedance - bandwidth. Formation of slits and slots on to the patch varies the results a lot since these depend on the shape of the patch; the position of the slit or slot formed will increase the electrical length of the patch to increase the impedance bandwidth. Axial ratio and gain are moderate.

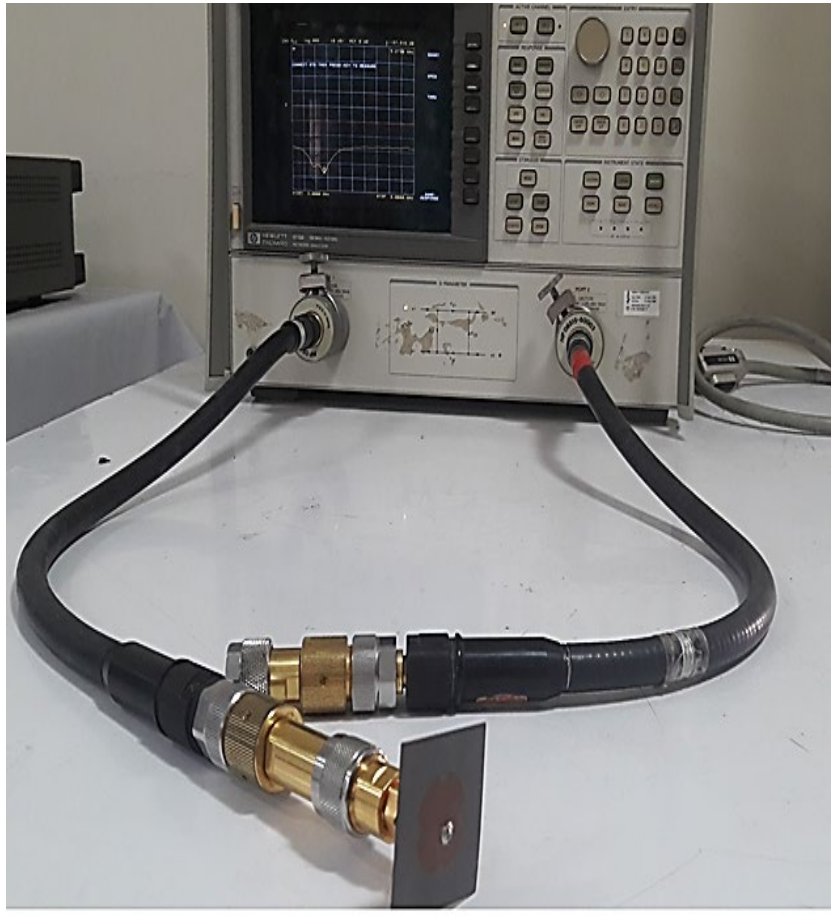

Fig. 14. An antenna connected to one port and matched load with other port. 


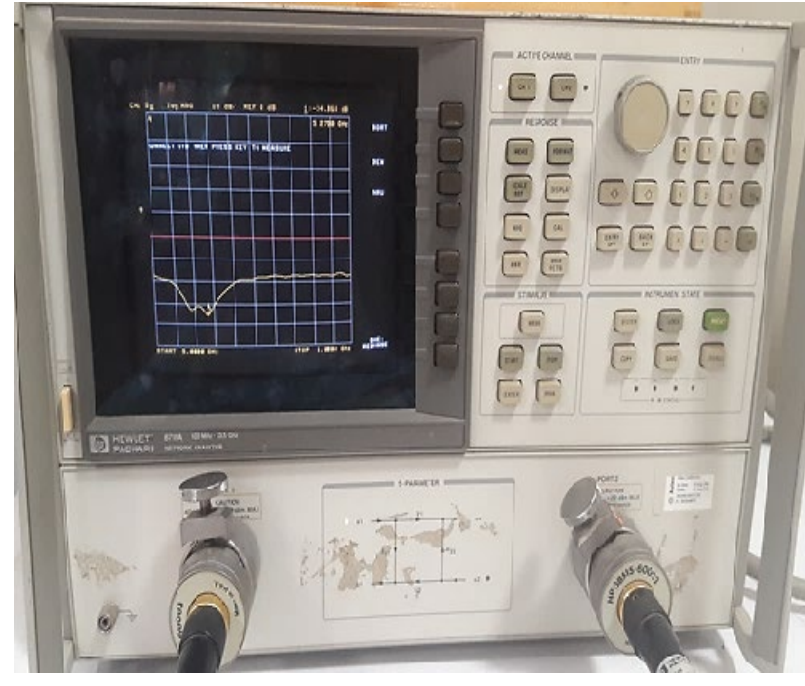

Fig. 15. Measured return loss for the CP antenna for 5G WLAN.

The proposed circularly polarized antenna is compared with similar antennas updated in the literature with respect to various design parameters, as shown in Table III. The measured results of the proposed antenna are in agreement with the simulated ones.

\section{CONCLUSION}

In the research, a compact semicircular microstrip patch $\mathrm{CP}$ antenna for 5G WLAN application has been reported. The size of the compact microstrip patch antenna is $36 \mathrm{~mm} \times 36 \mathrm{~mm} \times$ $0.787 \mathrm{~mm}$. By changing the radius $r_{2}$ at one corner of the semicircular slit, the desired resonant frequency band with circular polarization is achieved. A detailed description of how $\mathrm{CP}$ is obtained with slit formation at the corners is illustrated using surface current distribution at various time intervals. The specified fabricated design has been illustrated and compared with multiple existing models in terms of different performance parameters. A detailed description of techniques has been discussed and compared with the novelty of the design. The measurement setup has been described, and an antenna has been connected after matching the ports. A detailed picture of the fabricated microstrip patch antenna with a semi-circular slit connected to the network analyzer has been shown. The proposed structure gives better return loss, axial ratio, gain, and omnidirectional pattern. The resonant peak at $5.37 \mathrm{GHz}$ falls in $5 \mathrm{G}$ WLAN (5.1-5.725 GHz) and suitable for 5G WLAN applications.

\section{ACKNOWLEDGMENT}

The authors would like to express their most profound thankfulness towards the Department of ECE, NIT Warangal, for providing integral equation three-dimensional software and network analyzer setup.

\section{REFERENCES}

[1] E. Perahia and R. Stacey, Next Generation Wireless LANs. Cambridge University Press, 2009. https://doi.org/10.1017/CBO9780511541032

[2] E. H. Ong et al. "IEEE 802.11ac: Enhancements for Very High Throughput WLANs", IEEE 22nd International Symposium on Personal, Indoor and Mobile Radio Communications, 2011 https://doi.org/10.1109/PIMRC.2011.6140087

[3] A. Kumar, P. Vardhan, "Design, Simulation \& Concept Verification of 4 $\times 4,8 \times 8$ MIMO with ZF, MMSE and BF Detection Schemes", Electrical, Control and Communication Engineering 2017, vol. 13, no. 1, pp. 69-74. https://doi.org/10.1515/ecce-2017-0010

[4] G. A. Deschamps, "Microstrip Microwave Antennas," 3rd USAR Symposium on Antennas, vol. 1, pp. 189-195, 1953.

[5] K. R. Carver and J. W. Mink, "Microstrip Antenna Technology" IEEE Transactions on Antennas and Propagation, vol. 29, no. 1, January 1981. https://doi.org/10.1109/TAP.1981.1142523

[6] S. Ravikanti and L. Anjaneyulu, "A Survey on miniaturization of circularly polarized antennas for future wireless communications," in Electronics and Communications Engineering: Applications and Innovations, T. K. Kumar, R. K. Jatoth, \& V.V Mani (Eds). p. 63, 2019. https://doi.org/10.1201/9781351136822-7

[7] K. Ming, H. W. Lai, K. M. Luk and C. H. Chan, "Circularly polarized patch antenna for future 5G mobile phones," IEEE Access, vol. 2, pp. 1521-1529, 2014. https://doi.org/10.1109/ACCESS.2014.2382111

[8] H. Wong, Q. W. Lin, H. W. Lai, and X. Y. Zhang, "Substrate Integrated Meandering Probe-Fed Patch Antennas for Wideband Wireless Devices," IEEE Transactions on Components, Packaging and Manufacturing Technology, vol. 5, no. 3 March 2015. https://doi.org/10.1109/TCPMT.2015.2398846

[9] P. C. Sharma and K. C. Gupta, "Analysis and optimized design of single feed circularly polarized microstrip antennas," IEEE transactions on Antennas and Propagation, vol. AP-31, no. 6, November 1983. https://doi.org/10.1109/TAP.1983.1143162

[10] W. S. Chen, C. K. Wu, and K. L. Wong, "Single-feed square-ring microstrip antenna with truncated corners for compact circular polarization operation," Electron. Lett. vol. 34, no. 11, pp. 1045-1047, May 1998. https://doi.org/10.1049/el:19980818

[11] H. Wong, et al. "Virtually Shorted Patch Antenna for Circular Polarization," IEEE Antennas and Wireless Propagation Letters, vol. 9, 2010. https://doi.org/10.1109/LAWP.2010.2100361

[12] Nasimuddin, X. Qing, and Z. N. Chen "Compact Asymmetric-Slit Microstrip Antennas for Circular Polarization," IEEE Antennas Wireless Propag. Lett. vol. 59, no 1, Jan. 2011. https://doi.org/10.1109/TAP.2010.2090468

[13] A. Soltan, M. H. Neshati, "Development of Circularly Polarized Cavity Backed Slot Antennas Using SIW Structure," 3rd International Conference on Advances in Computational Tools for Engineering Applications (ACTEA), 2016. https://doi.org/10.1109/ACTEA.2016.7560111

[14] J. Liu, Y. Li, Z. Liang, and Y. Long, "A Planar Quasi Magnetic-Electric Circularly-Polarized Antenna," IEEE Transactions on Antennas and Propagation, vol. 64, no. 6, pp. 2108-2114, 2016. https://doi.org/10.1109/TAP.2016.2543783

[15] Nasimuddin, X. Qing, and Z. N. Chen, "A Compact Circularly Polarized Slotted Patch Antenna for GNSS Applications," IEEE Transactions on Antennas and Propagation, vol. 62, no. 12, December 2014. https://doi.org/10.1109/TAP.2014.2360218

[16] D. Wang, H. Wong, and C. H. Chan, "Small Circularly Polarized Patch Antenna," International Workshop on Antenna Technology (iWAT), 2011. https://doi.org/10.1109/IWAT.2011.5752326

[17] H. Iwasaki, "A Circularly Polarized Small-Size Microstrip Antenna with a Cross Slot," IEEE Transactions on Antennas and Propogation, vol. 44, no. 10, October 1996. https://doi.org/10.1109/8.537335

[18] A. Ferchichi and A. Gharsallah, "A Circuit Model to a Directive Triangular EBG Antenna," Int. Journal of Electronics and Telecommunications, 2013, vol. 59, no. 2, pp. 125-130. https://doi.org/10.2478/eletel-2013-0015

[19] W.-S. Chen, K.-L. Wong, and C.-K. Wu, "Inset Microstrip line-Fed Circularly Polarized Microstrip Antennas," IEEE Transactions on Aantennas and Propagation, vol. 48, no. 8, August 2000. https://doi.org/10.1109/8.884494 
[20] W. S. Chen, C. K. Wu, and K. L. Wong, "Compact circularly-polarized circular microstrip antenna with cross-slot and peripheral cuts," Electron. Lett., vol. 34, pp. 1040-1041, 1998. https://doi.org/10.1049/el:19980821

[21] S. Ravikanti, L. Anjaneyulu, "Compact Circularly Polarized Patch Antenna for WiMAX Applications with Improved Impedance Bandwidth and Axial Ratio" Engineering, Technology \& Applied Science Research vol. 10 , no. $1,2020$.

[22] R. Garg, P. Bhatia, I. Bahl, and A. Ittipboon, Microstrip Antenna Design Handbook. Norwood, MA: Artech House, 2001.

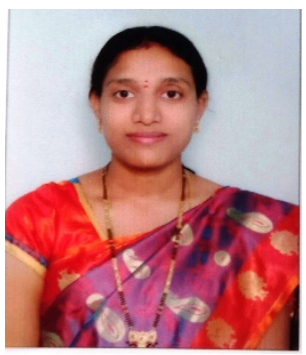

Swetha Ravikanti received B. Tech (ECE) from TKR College of Engineering and Technology and Science in 2008. She received M. Tech (Microwave and Radar Engineering) from Osmania University Hyderabad, India, in 2010. She has teaching experience of five years at various colleges in Hyderabad Telangana State, India, and is currently pursuing a $\mathrm{Ph}$. D. degree at the National Institute of Technology, Warangal, India. Her field of study is circularly polarized antennas for future wireless applications, and other areas of interest are microwave engineering, antenna and wave propagation and microstrip antennas.

Address: National Institute of Technology Warangal, Department of Electronics and Communications Engineering, Warangal District-506004, Telangana, India.

E-mail: swetha.rks@nitw.ac.in

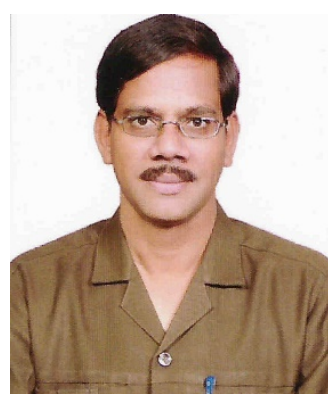

Prof L. Anjaneyulu was born in 1967 in India. He obtained his B. Tech (ECE) in 1989, M. Tech from R.E.C (N.I.T), Warangal in 1991, and $\mathrm{Ph}$. D. from N.I.T, Warangal. He worked as a Project Officer at the Institute of Armament Technology, Pune, India for 5 years from 1991 and was involved in the design of surface-borne and air-borne radar systems for clutter measurement application. Later, he worked as a Scientist at Helios Systems, Madras, India, for 2 years and was engaged in the development of radio wave propagation assessment software modules for ship-borne radars. He has been with the Department of Electronics and Communications Engineering at the National Institute of Technology, Warangal, India, since 1997 and has 22 years of teaching experience. His areas of interest include radar and microwave engineering, antennas, computer networks, neural networks \& fuzzy logic systems. He has completed few defence R\&D projects and has 60 papers to his credit in national and international conferences and journals. He is a Life Member of ISTE, Fellow of Institute of Engineers, Fellow of IETE and a member of IEEE, IEEE-APS. Currently, he is guiding six PhD scholars and one $\mathrm{PhD}$ has been awarded. He is a reviewer for the Defence Science Journal (DRDO), New Delhi. He has conducted several short-term training programes as a coordinator in the areas of computer networks, microwave and radar engineering, electromagnetic fields. He has 100 research papers to his credit in national and international journals and conferences.

Address: National Institute of Technology Warangal, Department of Electronics and Communications Engineering, Warangal District-506004, Telangana, India.

E-mail:anjan@nitw.ac.in 